\title{
PENERAPAN DEMOKRASI BERKEADABAN DALAM KEBUDAYAAN DAN TRADISI SUKU BUGIS
}

\author{
Gabriana Akhira Malik, Muhammad Sandi Putra Pratama Maso, Muhammad Ziyad \\ Akbar, \& Salsabila Fathona \\ Institut Teknologi Bandung \\ Email: 10420005@mahasiswa.itb.ac.id
}

\begin{abstract}
Abstrak
Dalam kebudayaan Bugis kuno atau dapat disebutjuga masa pra-Islam dan kolonial, terdapat suatu karya sastra yang berisi filosofi atau ajaran mengenai berbagai aspek kehidupan termasuk sistem politik dan kemasyarakatan yang dinamakan Lontarak Bugis. Pada naskah Lontarak ini banyak ditemukan hal-hal yang sebangun dengan nilai-nilai demokrasi dan hak asasi manusia (HAM) sebagaimana kita kenal sekarang. Lontarak Bugis ini juga menjadi sumber referensi dan refleksi bagi para pemegang otoritas kekuasaan di era Bugis purba. Penelitian ini bertujuan untuk memvalidasi kesesuaian antara demokrasi berkeadaban dengan kebudayaan salah satu suku di Indonesia, yaitu suku Bugis. Pengumpulan data dilakukan dengan studi literatur. Suku Bugis yang telah menerapkan demokrasi berkeadaban sejak abad 15 dan 16 membuktikan bahwa mereka menggunakan asas-asas demokrasi berkeadaban sebelum dunia barat menjadikannya pedoman dalam kehidupan bermasyarakat. Suku Bugis mempunyai sistem adat mengenai bentuk demokrasi dalam menyuarakan suara rakyat yang disebut sistem norma Pangngadereng. Dari penelitian ini, diharapkan dapat menambah pengetahuan masyarakat terutama mahasiswa ITB mengenai sistem demokrasi di salah satu daerah di Indonesia. Selain itu, sistem demokrasi di kebudayaan Bugis dapat menjadi contoh untuk masyarakat lain dalam menerapkan sistem demokrasi di daerahnya.
\end{abstract}

Kata Kunci: Suku Bugis, Demokrasi Berkeadaban, Kebudayaan

\begin{abstract}
In ancient Bugis culture or it can also be called the pre-Islamic and colonial period, there is a literature work that contains philosophy or teachings regarding various aspects of life including the political and social system called Lontarak Bugis. In this Lontarak manuscript, many things are found that are congruent with the values of democracy and human rights as we know it today. This Bugis Lontarak is also a source of reference and reflection for the authorities in the ancient Bugis era. This study aims to validate the compatibility between civilized democracy and the culture of one of the tribes in Indonesia, namely the Bugis. Data was collected by means of a literature study. The Bugis who have implemented civilized democracy since the 15th and 16th centuries have proven that they used the principles of civilized democracy before the western made them a guide in their social life. The Bugis tribe has a customary system regarding the form of democracy in voicing the people's voice which is called the Pangngadereng norm system. From this research, it is hoped that it can increase public knowledge especially ITB students about the democratic system in one of the tribes in Indonesia. Furthermore, the democratic system in Bugis culture can be an example for other communities in implementing the democratic system in their area.
\end{abstract}

Keywords: Bugis Tribe, Civilized Democracy, Culture

\section{PENDAHULUAN}

Demokrasi berkeadaban dapat diartikan sebagai sebuah sistem pemerintahan berlandaskan nilai-nilai keadaban dan kesopanan dengan mengutamakan persamaan hak dan kewajiban warga negaranya. Bangsa Indonesia kini tengah memasuki era reformasi dalam upaya membangun demokrasi yang berkeadaban. Namun, pelaksanaan demokrasi yang seringkali dibahas tersebut terasa sangat sulit untuk diimplementasikan yang terlihat dari berbagai peristiwa yang terjadi di Indonesia. 
Ditandai dengan adanya pembatasan dalam berpendapat dan berekspresi mengenai kebijakan pemerintah. Terhitung terdapat 26 kasus pembatasan kebebasan berpendapat yang sudah terjadi selama pemerintahan saat ini (Mangihot: 2021). Salah satunya adalah kritik terhadap pemerintah yang diekspresikan lewat media, seperti mural. Padahal, salah satu suku di Indonesia telah menerapkan nilainilai demokrasi berkeadaban dengan memberikan kebebasan berpendapat dan berekspresi kepada masyarakatnya. Suku tersebut adalah Suku Bugis yang berasal dari Provinsi Sulawesi Selatan.

Suku Bugis dikenal sebagai suku yang sangat memperhatikan kedaulatan masyarakatnya. Suku Bugis memiliki sistem norma yang mengatur demokrasi dalam kebebasan berpendapat bernama sistem norma Pangngadereng. Bahkan sistem norma tersebut sudah diterapkan oleh suku Bugis sebelum dunia barat menjadikannya pedoman dalam kehidupan bermasyarakat (Darmayana: 2011). Sistem norma yang dimiliki oleh suku Bugis seharusnya dapat diimplementasikan dalam demokrasi di Indonesia karena erat kaitannya dengan masalah demokrasi yang terjadi saat ini.

\section{METODE PENELITIAN}

Pada penelitian ini, penulis menggunakan metode studi literatur dengan cara menggunakan referensi berupa buku, artikel, dan jurnal. Studi literatur dimulai dari mengetahui jenis pustaka yang dibutuhkan, mengkaji dan mengumpulkan bahan pustaka yang dilakukan dengan menggunakan alat bantu yang disebut kartu kutipan, dan menyajikan studi kepustakaan penyajian studi kepustakaan dapat dilakukan dengan cara kutipan langsung dan kutipan tidak langsung. Teknik ini dilakukan dengan tujuan untuk mengungkapkan berbagai teori yang relevan dengan permasalahan yang diteliti sebagai bahan rujukan dalam pembahasan hasil penelitian.

\section{HASIL PENELITIAN DAN PEMBAHASAN Hasil Penelitian Pengertian Demokrasi}

Secara etimologis, demokrasi berasal dari bahasa Yunani yang terdiri dari dua kata, yaitu demos dan cratos. Demos berarti rakyat dan cratos berarti pemerintahan atau kekuasaan. Jika digabungkan, demokrasi dapat diartikan sebagai pemerintahan rakyat atau kekuasaan rakyat. Sedangkan, para ahli juga mengartikan demokrasi dengan pemahaman yang berbeda-beda (Dewi \& Al-khansa: 2021, hlm. 2723-2328) (Nurgiansah, 2021). Berikut merupakan pengertian demokrasi menurut para ahli:

1. Demokrasi menurut Abraham Lincoln adalah sebuah sistem pemerintahan yang dibentuk dari rakyat, oleh rakyat, dan untuk rakyat itu sendiri.

2. Demokrasi menurut Charles Costello adalah suatu sistem sosial dan politik yang mana kekuasaan pemerintahan dibatasi oleh hukum dan juga budaya yang melindungi segenap hak perorangan dari warga negara itu sendiri.

3. Demokrasi menurut Hans Kelsen adalah suatu pemerintahan yang diadakan dan dilaksanakan dari rakyat dan untuk rakyat, serta mengenai pelaksanaan kekuasaan negaranya adalah wakil dari rakyat yang sudah dipilih oleh rakyat setelah adanya keyakinan terhadap aturan yang telah ditetapkan berhubungan dengan penerapan dari kekuasaan negara.

Menurut KBBI, demokrasi adalah bentuk pemerintahan yang seluruh rakyatnya turut serta memerintah dengan perantaraan wakilnya. Sedangkan, keadaban adalah ketinggian tingkat kecerdasan lahir batin ataupun kebaikan 
budi pekerti. Maka dapat disimpulkan bahwa pengertian dari demokrasi berkeadaban itu sendiri adalah sebuah sistem pemerintahan berlandaskan nilainilai keadaban dan kesopanan dengan mengutamakan persamaan hak dan kewajiban warga negaranya. Dengan mewujudkan demokrasi yang berkeadaban, diharapkan dapat membangun sebuah sistem politik yang baik dan berkualitas sehingga mampu menghasilkan kebijakankebijakan yang menjunjung nilai-nilai Pancasila dan pro terhadap keberlangsungan hidup masyarakat.

\section{Pembahasan}

\section{Maraknya Demokrasi di Indonesia}

Demokrasi yang terjadi pada periode 1945-1959 dikenal dengan sebutan Demokrasi Parlementer yang mulai berlaku semenjak sebulan sesudah kemerdekaan diproklamirkan dan mulai diperkuat dalam Undang Undang Dasar 1945 dan 1950. Sistem pemerintahan yang parlemen mempunyai peran penting. Pada sistem ini, rakyat memiliki kekuasaan untuk ikut campur urusan politik dan boleh membuat partai. Anggota kabinet juga diperbolehkan mengkritik pemerintah setuju terhadap sesuatu.

Walaupun begitu, demokrasi parlementer kurang cocok untuk Indonesia, meskipun dapat berjalan lancar di negaranegara Asia lainnya. Demokrasi selanjutnya yang terjadi pada periode 1959-1965 disebut dengan sebutan Demokrasi Terpimpin, sistem demokrasi yang seluruh keputusan serta pemikiran berpusat pada pemimpin negara. Pada era ini, terjadi dominasi politik presiden dan berkembangnya pengaruh komunis dan peranan tentara (ABRI) dalam politik Indonesia. Demokrasi terpimpin bukanlah demokrasi yang sebenarnya, melainkan sebagai bentuk keotoriteran yang tidak mencerminkan arti dari demokrasi itu sendiri. Demokrasi terpimpin dari Soekarno berakhir dengan lahirnya Gerakan 30 September PKI (G30SPKI).

Demokrasi Pancasila atau Orde Baru terjadi pada periode 1965-1998. Periode pemerintahan ini muncul setelah gagalnya G30SPKI yang dilandasi oleh prinsipprinsip yang terdapat dalam pancasila. Demokrasi Pancasila juga menawarkan tiga komponen demokrasi, yaitu menegakkan kembali asas-asas negara hukum dan kepastian hukum, mengutamakan kehidupan yang layak bagi semua warga negara, serta pengakuan, perlindungan HAM, dan peradilan yang bebas dan tidak memihak (Welianto: 2019) (Nurgiansah, 2020).

Pelaksanaan demokrasi di era reformasi, yaitu periode 1998-sekarang ditandai dengan lengsernya presiden terdahulu, Soeharto yang menjabat sebagai presiden selama sekitar 32 tahun. Demokrasi Indonesia periode reformasi meletakkan fondasi yang kuat bagi pelaksanaan demokrasi Indonesia pada masa selanjutnya. Dalam periode ini, tuntutan rakyat yang berawal dari lengsernya Presiden Soeharto mengenai pelaksanaan demokrasi dan HAM harus lebih konsekuen. Banyak terjadi perombakan secara aturan, fungsi, dan institusi karena cita-cita demokrasi yang menjunjung tinggi HAM (Putri: 2019).

\section{Tradisi Bugis}

Indonesia telah menerapkan jenisjenis demokrasi dari sebelum kemerdekaan Indonesia. Penerapan demokrasi sudah diterapkan oleh suku Bugis sekitar akhir abad ke-15 dan awal abad ke-16. Berdasarkan karya dari Professor Andi Abidin, sejak dulu sudah ditemukan tatanan masyarakat yang demokratis pada masyarakat Wajo'. Pembahasan ini bertujuan untuk mengeksplorasi secara khusus nilai-nilai dan praktik demokrasi dalam kehidupan sosial budaya, politik, dan hukum masyarakat Wajo', khususnya di era 
kerajaan historisnya (Abidin: 1985). Menurut Anderson, kerajaan-kerajaan Bugis tradisional memiliki tiga ciri utama, yaitu:

(1) Bersifat konfederatif (gabungan antara kerajaan-kerajaan kecil),

(2) Adanya penguasa tertinggi (paramount rulers), dan

(3) Adanya batas-batas teritorial.

Setiap kerajaan Bugis adalah konfederasi unit-unit politik yang lebih kecil (limpo) yang menggabungkan diri dalam rangka keuntungan bersama dan karena prestise menjadi bagian dari suatu garis keturunan tertentu (Anderson: 2003) (Nurgiansah, 2018).

Masyarakat Bugis memiliki salah satu perjanjian dengan La Paléwo To Palipu' atau disebut juga Arung Matoa Wajo' yang disebutkan bahwa seorang raja memiliki kewajiban untuk mengayomi, memelihara dan mensejahterakan rakyatnya (Abidin: 1985). Dengan adanya perjanjian antara raja dan rakyatnya, kerajaan-kerajaan di Sulawesi bagian selatan di awal abad ke-15 dianggap memiliki keunikan di antara kerajaan lain di Nusantara pada periode yang sama. Sistem pemerintahan Bugis memiliki bentuk monarki absolut. Walaupun di setiap kerajaan Bugis terdapat pemegang kekuasaan tertinggi (misalnya, Arung Matoa di Wajo', Arumpone di Bone, Pajung di Luwu'), pemegang kekuasaan tersebut tidak dapat mengubah sistem kerajaan menjadi otokrasi. Selain itu, mereka tidak dapat melakukan perubahan sewenang-wenang. Salah satunya adalah hukum adat yang tidak boleh diubah dan harus dipatuhi (Anderson: 2003).

Terdapat beberapa alasan mengapa kerajaan-kerajaan di Wajo' memiliki keunikan tersendiri dibandingkan kerajaan lainnya. Pertama, kerajaan di Wajo' memiliki hukum adat yang menjamin hakhak kebebasan rakyat atau biasa disebut juga sebagai B. ade'. Jika terdapat perintah yang bertentangan dengan konsesus orangorang Wajo', maka orang-orang Wajo' tidak dapat terikat oleh perintah tersebut.

Kedua, raja Wajo' yang terpilih tidak dipilih berdasarkan turun-temurun, melainkan dipilih oleh suatu lembaga yang dikenal sebagai Arung Patappuloé (pertuanan 40 orang). Ketiga, dalam perumusan hukum adat yang dinamakan dengan "ade' assituruseng", keputusan yang diambil dilakukan dengan cara pemungutan suara terbanyak (voting). Perubahan atau amandemen dan pembatalan terhadap ade' assituruseng ini pun harus dilakukan baik dengan cara musyawarah untuk mufakat (B. assipétanngareng) maupun pemungutan suara (Mattulada: 1985).

Keempat, dalam kerajaan Wajo', terdapat suatu jabatan yang berfungsi sebagai pembela rakyat yang disebut juga sebagai Arung Saotanré. Pejabat ini bertugas secara khusus untuk membela hak-hak asasi rakyat jika dilanggar oleh raja atau pejabat-pejabat lain dalam kerajaan. Kelima, ada aspek keadilan dan persamaan di hadapan hukum (B. bicara) di dalam masyarakat Wajo'. Aspek ini menunjukkan bahwa Kerajaan Wajo' telah lebih dulu menegakkan keadilan di dalam hukum sebelum traktat dan konvensi hukum di negara-negara Barat diperkenalkan secara global (Halim: 2016, hlm. 1-16).

Berdasarkan paparan di atas, terlihat bahwa penegakan prinsip demokrasi telah dilakukan dalam kehidupan masyarakat Wajo'. Selain itu, ada kesamaan dan kesetaraan dalam kehidupan sosial budaya, ekonomi, dan politik. Faktor yang membuat prinsip tersebut bisa ditegakkan adalah kebebasan masyarakat Wajo' yang dijamin oleh adat. Tidak ada seorang pun termasuk raja yang dapat memaksa rakyat untuk melakukan sesuatu yang bertentangan dengan adat. Masyarakat Wajo' dapat dengan bebas untuk menentukan masa depan mereka (Halim: 2016, hlm. 1-16). 


\section{Membangun Masyarakat yang Berdemokrasi Berkeadaban}

Membangun masyarakat yang berdemokrasi berkeadaban dapat dimulai dari tingkat sekolah. Sejak tahun 1960an kita telah mengenal mata pelajaran "Civic" di Sekolah Dasar yang merupakan embryo dari "Civic Education" (Nadziroh: 2015, hlm. 263-266). Selain itu, penanaman nilai demokrasi dapat diterapkan dalam bentuk kegiatan organisasi di sekolah. Penanaman nilai-nilai kemanusiaan yang adil dan beradab dapat dibentuk dalam beberapa organisasi di sekolah, seperti Organisasi Siswa Intra Sekolah (OSIS) dan pramuka. Kegiatan berorganisasi tersebut dapat menumbuhkan nilai-nilai keadaban, seperti menghargai antar sesama (Dewi \& Alkhansa: 2021, hlm. 2723-2328).

Pengertian demokrasi secara umum adalah kebebasan dalam mengemukakan pendapat. Suatu demokrasi dapat dikatakan berkualitas jika menjunjung tinggi nilainilai Pancasila terutama nilai keadaban. Demokrasi berkeadaban berarti menjunjung tinggi nilai keadaban dan kesopanan. Maka, sangat penting bagi setiap elemen masyarakat dalam berdemokrasi untuk tidak menimbulkan perpecahan antar masyarakat, berbangsa maupun bernegara.

Cerminan karakter bangsa yang berbudi pekerti luhur untuk saat ini adalah membangun masyarakat demokrasi yang berkeadaban. Terkadang masyarakat sudah lupa akan nilai-nilai keberadaban karena seringnya permusuhan antar sesama. Terkadang juga masyarakat sering menyalah artikan definisi dari demokrasi itu sendiri. Maka dari itu diperlukan kesadaran oleh warga negara untuk menjadi menjadi warga negara yang cerdas yang mampu menggunakan akal budinya dengan baik. Semua manusia memahami mana yang benar dan mana yang salah, jika akal budi kita digunakan untuk hal yang baik maka terjalinlah kebersamaan antar masyarakat atau timbulnya rasa keharmonisan dan ketenteraman dalam suatu negara (Nurgiansah, 2019).

\section{Penanaman Nilai-nilai Demokrasi Berkeadaban}

Menurut Prof. Dr. Kaelan, M.S., salah satu Guru Besar di Universitas Gadjah Mada mengatakan di tahun 2014 silam bahwa demokrasi di Indonesia masih jauh dari nilai-nilai keadaban. Alasannya adalah karena demokrasi dewasa ini yang kuat menindas yang lemah, yaitu yang kuat kekuasaannya, yang kuat kekayaannya, yang kuat kapital dan modalnya, serta yang kuat kepopulerannya. Artinya, demokrasi di Indonesia hanya dinikmati oleh kapitalis dan elit negara saja. Bagaimana sebuah demokrasi dikatakan telah memenuhi nilainilai keadaban jika tidak memberikan ruang kepada kelompok kecil, kalangan etnis minoritas, suku, ras, golongan, agama dan sebagainya (Agung: 2014).

Berdasarkan pendapat yang telah dikemukakan pada paragraf sebelumnya, diketahui bahwa pelaksanaan demokrasi di Indonesia setelah reformasi masih belum menanamkan nilai-nilai demokrasi berkeadaban. Hal ini berbeda dengan apa yang telah dilakukan oleh rakyat Wajo' yang sejak dulu rakyat selalu dilibatkan dalam pemerintahan. Pemimpin mereka yang disebut sebagai seorang raja memiliki kewajiban untuk mengayomi, memelihara dan mensejahterakan rakyatnya. Selain itu di dalam kehidupan masyarakat Wajo' ada kesetaraan dalam kehidupan sosial politik, ekonomi dan politik.

Pelaksanaan demokrasi berkeadaban di Indonesia seharusnya berlandaskan pada Pancasila khususnya sila ke-2 yang berbunyi "Kemanusiaan yang Adil dan Beradab". Dalam mewujudkan terciptanya demokrasi yang berkeadaban, diperlukan kesadaran dalam masyarakat untuk selalu menjunjung nilai-nilai Pancasila dalam setiap aspek kehidupan yaitu sosial, 
ekonomi dan politik. Untuk mencapai hal tersebut, mungkin bisa dimulai dari komitmen yang kuat dan keberanian moral dari para pemimpin bangsa untuk membawa kembali nilai-nilai Pancasila dalam kehidupan masyarakat. Ini bertujuan agar masyarakat semakin sadar untuk selalu memposisikan Pancasila dalam setiap aspek masalah, terutama demokrasi (Yuniarto: 2014).

Para pemimpin bangsa saat ini mungkin juga perlu berkaca kepada pemimpin-pemimpin rakyat Wajo' yang selalu mengayomi rakyatnya. Faktor keteladanan para pemimpin bangsa dalam mempraktekkan budaya kehidupan berPancasila dapat menjadi contoh yang baik untuk masyarakat untuk membuat masyarakat semakin sadar akan pentingnya Pancasila. Jika kesadaran akan nilai-nilai Pancasila makin kuat, maka seharusnya pelaksanaan demokrasi di Indonesia akan berlandaskan pada jati diri bangsa dan nilai-nilai budi pekerti luhur sehingga pelaksanaan demokrasi berkeadaban yang kita inginkan dapat terlaksana (Yuniarto: 2014).

\section{Manfaat Hasil Penelitian bagi Ilmu Pengetahuan/Masyarakat}

Manfaat dari penelitian ini, yaitu dapat menambah pengetahuan masyarakat terutama mahasiswa ITB mengenai sistem demokrasi di salah satu daerah di
Indonesia. Selain itu, sistem demokrasi di kebudayaan Bugis khususnya pada masyarakat Wajo' dapat menjadi contoh untuk masyarakat lain dalam menerapkan sistem demokrasi di daerahnya masingmasing.

\section{KESIMPULAN}

Berdasarkan literatur yang dipaparkan dalam setiap paragraf, terlihat bahwa selama masa kerajaan, prinsip utama demokrasi telah dipraktikkan dalam kehidupan masyarakat Wajo' sejak abad ke15 hingga akhir abad ke-16. Demokrasi yang ditegakkan pada saat itu sesuai dengan prinsip demokrasi berkeadaban yang seharusnya diterapkan pada masa sekarang. Hal itu bisa dibuktikan dengan kenyataan bahwa sejak periode formatif Wajo' tersebut telah terlihat, seperti adanya penghargaan, jaminan, dan perlindungan terhadap hak kebebasan rakyat, pemilihan pemimpin, dewan perwakilan rakyat, distribusi kekuasaan ke wilayah kecil, serta penegakan hukum yang tegas dan adil. Selain itu, sudah ada prinsip kesetaraan peluang dan kesempatan bagi seluruh rakyat Wajo' yang bisa diterapkan karena dalam era kerajaan historis, ade' (adat) ditempatkan pada puncak piramida kekuasaan dalam masyarakat. Bahkan, dalam perspektif yang luas, adat bagi orang Wajo' adalah segala-galanya.

\section{DAFTAR PUSTAKA}

Abidin, A. Z. 1985. Wajo' pada Abad XV-XVI: Suatu Penggalian Sejarah Terpendam Sulawesi Selatan. Bandung: Alumni.

Agung. 2014. Proses Demokrasi Masih Jauh dari Keadaban. (www.ugm.ac.id/id/berita/ 8782proses-demokrasi-masih-jauh-dari-keadaban), diakses 15 November 2021.

Anderson, K. G. 2003. The Open Door: Early Modern Wajo'rese Statecraft dan Diaspora. Honolulu: Universitas Hawai'i.

Darmayana, H. 2011. Falsafah Demokrasi Dalam Kebudayaan Bugis. (https://www.berdikarionline.com/falsafah-demokrasi-dalam-kebudayaan-bugis), diakses 16 November 2021. 
Dewi, D. A., \& Al-khansa, B. B. 2021. Pendidikan Kewarganegaraan: Membangun Masyarakat Demokrasi yang Berkeadaban Dari Saat Ini. Jurnal Kewarganegaraan, 5(1), p. 2723 2328.

Halim, W. 2016. Eksplorasi atas Praktik dan Nilai-nilai Demokrasi Dalam Kerajaan Wajo Abad ke-15/16 dan Kompatibilitasnya Dengan Sistem Demokrasi Modern. Jurnal Masyarakat \& Budaya, 18(2), p. 1-16.

Mangihot, J. 2021. Kontras: Ada 26 Kasus yang Dilakukan Pemerintah Jokowi Terkait Pembatasan Kebebasan Berpendapat. (https://www.kompas.tv/article/211532/kontras-ada-26kasus-yang-dilakukan-pemerintah-jokowi-terkait-pembatasan-kebebasanberpendapat), diakses 15 November 2021.

Mattulada. 1985. Latoa: Satu Lukisan Analitis terhadap Antropologi Politik Orang Bugis. Yogyakarta: Gajah Mada University Press.

Nadziroh. 2015. Membangun Masyarakat Demokratis Melalui Pendidikan Kewarganegaraan. Jurnal Pendidikan Ke-SD-an, 2(1), p. 263-266.

Nurgiansah, T. H. (2018). Pengembangan Kesadaran Hukum Berlalu Lintas Siswa Melalui Model Pembelajaran Jurisprudensial Dalam Pendidikan Kewarganegaraan (Studi Kasus di SMK Bina Essa Kabupaten Bandung Barat Kelas X Administrasi Perkantoran). Tesis. Repository Universitas Pendidikan Indonesia, Oktober. http://ieeeauthorcenter.ieee.org/wpcontent/uploads/IEEE-Reference-

Guide.pdf\%0Ahttp://wwwlib.murdoch.edu.au/find/citation/ieee.html\%0Ahttps://doi.or g/10.1016/j.cie.2019.07.022\%0Ahttps://github.com/ethereum/wiki/wiki/White-

Paper\%0Ahttps://tore.tuhh.de/hand

Nurgiansah, T. H. (2019). Pemutakhiran Kurikulum Pendidikan Kewarganegaraan di Era Revolusi Industri 4.0. Prosiding Seminar Kewarganegaraan Universitas Negeri Medan, 1(1), 95-102.

Nurgiansah, T. H. (2020). Filsafat Pendidikan. In Banyumas: CV Pena Persada.

Nurgiansah, T. H. (2021). Pendidikan Pancasila. In Solok: CV Mitra Cendekia Media.

Putri, A. S. 2020. Karakteristik Demokrasi Periode Reformasi (1998-sekarang). (https://www.kompas.com/skola/read/2020/02/13/160000569/karakteristikdemokrasi-periode-reformasi-1998-sekarang), diakses 16 November 2021.

Welianto, A. 2019. Sistem Demokrasi di Indonesia. (https://www.kompas.com/ skola/read/2019/12/11/201742369/ sistem-demokrasi-di-indonesia), diakses 16 November 2021.

Yuniarto, B. 2018. Pendidikan Demokrasi dan Budaya Demokrasi Konstitusional. (https://core.ac.uk/download/pdf/147421836.pdf), diakses 19 November 2021. 